Tropical Journal of Pharmaceutical Research June 2012; 11 (3): 371-378

(C) Pharmacotherapy Group Faculty of Pharmacy, University of Benin

Benin City, 300001 Nigeria.

All rights reserved.

Available online at http://www.tjpr.org

Research Article

http://dx.doi.org/10.4314/tjpr.v11i3.5

\title{
Evaluation of a Weakly Cationic Exchange Poly (Methacrylic Acid-Co-Divinylbenzene) Resin as Filler- Binder for Direct Compression Tablets
}

\author{
Prasert Akkaramongkolporn*, Tanasait Ngawhirunpat and Praneet \\ Opanasopit \\ Faculty of Pharmacy, Silpakorn University, Nakhon Pathom 73000, Thailand
}

\begin{abstract}
Purpose: To evaluate a weakly cationic exchange poly(methacrylic acid-co-divinylbenzene) resin (PMD) as a new filler-binder for direct compression tablets.

Methods: Powder properties of PMD and MCC were characterized. Tablets made from PMD and MCC with and without propranolol hydrochloride were evaluated for diameter, thickness, friability, assay, disintegration, dissolution and compression behavior.

Results: Tablets made from PMD (thickness: 3.54 - $4.46 \mathrm{~mm}$ ) were thicker than those of MCC (2.93 $3.33 \mathrm{~mm}$ ). At compression pressures $\geq 309 \mathrm{MPa}$, the crushing strength of PMD tablets was so high that it exceeded the capacity of the tester $(500 \mathrm{~N})$. PMD tablets rapidly disintegrated $(0.43-9.56 \mathrm{~min})$, but MCC tablets did not disintegrate within $60 \mathrm{~min}$. The crushing strength of PMD tablets containing 10 and $100 \mathrm{mg}$ propranolol hydrochloride was 406.1 and $177.9 \mathrm{~N}$, respectively, which were lower than that of tablets without the drug. Tablets made from PMD also exhibited faster drug dissolution. The slopes of the linear portions of Heckel plots for PMD and MCC were comparable $\left(5.02 \times 10^{-3}\right.$ and $\left.5.12 \times 10^{-3} \mathrm{MPa}^{-1}\right)$, respectively.

Conclusion: PMD has good compressibility at high compression pressures, which should make it a suitable filler-binder for direct compression tablets.
\end{abstract}

Keywords: Poly(methacrylic acid-co-divinylbenzene), Microcrystalline cellulose, Filler-binder, Direct compression tablet, Heckel plots. 


\section{INTRODUCTION}

Ease of manufacturing, convenience in administration, accurate dosing, good stability, low cost, etc. make tablets still the most widely used dosage form [1]. To this end, tablet manufacturing by direct compression is of special interest because production requires fewer processing steps, instruments and time compared with wet granulation. Moreover, it offers a tablet manufacturing route to drug substances that are particularly heat- and moisture-labile. Nonetheless, the quality of directly compressed tablets is highly dictated by the characteristics of starting excipients. Tablets containing a high amount of excipients and drug substances that have poor compressibility may not be prepared by direct compression. Due to this limitation, a compressible filler, referred to as "fillerbinder", is developed specially for direct compression tablets.

Though several filler-binders are available in the market, efforts to find more compressible filler-binders or that have multifunctions, persist [2-4]. For examples, a free-flowing form of calcium lactate pentahydrate has been found to be an effective filler-binder for direct compression [2]. Kumar and Medina developed and evaluated novel cellulose II powders as multifunctional filler-binders in the formulation of direct compression tablets $[3,4]$. The ibuprofen tablets prepared by the cellulose II powders met the accepted disintegration and dissolution qualities specified for a USP pharmaceutical tablet, without the addition of a disintegrant [4].

Poly(methacrylic acid-co-divinylbenzene) (PMD) is a weakly cationic exchange resin, which is primarily used as drug carrier for the development of controlled release dosage forms. Due to its ability to swell in water, the resin is also used as a disintegrant in tablet formulations [5]. To the best of our knowledge, the resin has never been described as a fillerbinder. However, in our previous work, it seemed that the resin was directly compressible [6]. Therefore, this study was aimed at evaluating PMD as a filler-binder for direct compression tablets, and comparing it with the widely used filler-binder, microcrystalline cellulose (MCC).

\section{EXPERIMENTAL}

\section{Materials}

Poly(methacrylic acid-co-divinylbenzene) (Amberlite IRP $64^{\circledR}$, Sigma Chemical Co., USA), microcrystalline cellulose (Avicel $\mathrm{PH}$ $102^{\circledR}$, FMC Corporation, USA) and propranolol hydrochloride (Changzhou Yabang Pharmaceutical Co., China) were purchased and used as received. The rest of the chemicals used were of analytical grade.

\section{Powder characterization}

The morphology of the test and standard fillerbinders was viewed $(\times 500$ magnification) with a scanning electron microscope (SEM, CamScan MX 2000, UK). The particle size was determined in triplicate by a laser scattering particle size distribution analyzer (Partica LA 950, Japan). Two grams of samples were used in each run. The particle size and size distribution were presented as the diameter which occupied $50 \%$ of cumulatively undersized particles $\left(d_{50}\right)$ and the polydispersity index (PI), respectively [7].

True density was determined with a helium gas pycnometer (Micromeritics 1305, USA) on $1 \mathrm{~g}$ samples of the powder. Bulk and tap densities were determined as follows. Fifteen grams of each sample were weighed and poured in a $25 \mathrm{ml}$ tarred graduate cylinder. The cylinder was gently tapped three times and the bulk volume read to determine bulk density (ratio of weight to volume). For tap density, the cylinder was further tapped to constant volume, tap density computed (ratio of weight to volume). All density determinations were in triplicate.

Flowability of the powders was assessed based on compressibility index and Hausner 
ratio according to Eqs 1 and 2, respectively [8].

$$
\begin{aligned}
& \text { Compressibility index }=\left(\frac{d_{\text {tap }}-d_{\text {bulk }}}{d_{\text {tap }}}\right) \times 100 \ldots \ldots .(1) \\
& \text { Hausner ratio }=\frac{d_{\text {tap }}}{d_{\text {bulk }}} \ldots \ldots \ldots \ldots \ldots . . .(2)
\end{aligned}
$$

where $d_{\text {bulk }}$ and $d_{\text {tap }}$ are the bulk and tap densities, respectively.

The degree of swelling of the filler-binders was volumetrically and gravimetrically determined in triplicate as follows. One gram of sample was weighed and placed in a $10 \mathrm{ml}$ cylinder. The cylinder was tapped to constant volume $\left(v_{0}\right)$ which was recorded. An excess amount of deionized water was added to the cylinder and $2 \mathrm{~h}$ later, the volume of the swollen sample $\left(\mathrm{v}_{1}\right)$ was recorded, and the volumetric swelling (\%) calculated as in Eq 3 [6].

Volumetric swelling $=\left(\frac{\mathrm{v}_{1}-\mathrm{v}_{0}}{\mathrm{v}_{0}}\right) \times 100 \ldots \ldots \ldots \ldots . . .(3)$

Gravimetric swelling was determined by placing $1 \mathrm{~g}$ of sample $\left(\mathrm{w}_{0}\right)$ on a filter paper that has been wetted with water whose weight (wet paper) had been recorded. An excess amount of deionized water was added and left to wet the sample for $2 \mathrm{~h}$. Thereafter, the water was drained off, and the weight of the swollen sample was calculated $\left(w_{1}\right)$ by subtracting the final from initial weight of the wetted filter paper. Gravimetric swelling (\%) was calculated as in Eq 4 [9].

Gravimetric swelling $=\left(\frac{\mathrm{w}_{1}-\mathrm{w}_{0}}{\mathrm{w}_{0}}\right) \times 100$

\section{Preparation of tablets}

Each filler-binder (300 mg) was accurately weighed on an analytical balance, and placed in the die of a hydraulic hand press (Specac P/N 15011/25011, UK), and compressed using stainless steel flat-faced cylindrical punches $(9.35 \mathrm{~mm}$ in diameter) at pressures ranging from 34 to $344 \mathrm{MPa}$ and a constant dwelling time of $5 \mathrm{~s}$.
Tablets $(300 \mathrm{mg})$ containing a mixture of propranolol hydrochloride (10 or $100 \mathrm{mg}$ ) and a filler-binder (PMD or MCC) were also prepared. The tablets were compressed at $344 \mathrm{MPa}$ using the tablet press indicated above and at the same dwelling time. The tablets were stored in sealed containers until evaluation.

\section{Evaluation of tablets}

Thickness and diameter of ten tablets from each batch were measured with a dial caliper (Peacock G, Japan). Crushing strength was measured with a texture analyzer (Stable Micro Systems TA.XT plus, UK). In this measurement, ten tablets were individually pressed by a stainless steel flat-faced $(6 \mathrm{~mm}$ in diameter) cylindrical probe moving at 0.1 $\mathrm{mm} / \mathrm{s}$. The crushing strength was the pressure that caused a diametrical break in the tablet. Friability was determined with a Roche friabilator. Ten tablets were weighed $\left(m_{0}\right)$ and placed in the friabilator operating at $25 \mathrm{rev} / \mathrm{min}$ for $4 \mathrm{~min}$. After removal of fines, the tablets were re-weighed $\left(m_{1}\right)$, and the friability (\%) was calculated by Eq 5 [8].

Friability $=\left(\frac{\mathrm{m}_{0}-\mathrm{m}_{1}}{\mathrm{~m}_{0}}\right) \times 100$.

Disintegration test was conducted in a USP disintegration tester (Sotax DT 3, Switzerland) in deionized water and $0.1 \mathrm{M} \mathrm{HCl}$ maintained at $37 \pm 1{ }^{\circ} \mathrm{C}$ for tablet with and without drug content. Dissolution test was determined using a USP basket type dissolution apparatus (Dissolutest Prolabo, France) in $1000 \mathrm{ml}$ of $0.1 \mathrm{M} \mathrm{HCl}$ at $37 \pm 1{ }^{\circ} \mathrm{C}$, with the basket rotated at $100 \mathrm{rev} / \mathrm{min}$ [8]. The dissolved drug was assayed by an ultraviolet spectrophotometer (UV, Agilent 8453 E, USA) at $289 \mathrm{~nm}$. Six tablets from each batch were for this test.

Drug content was determined by a developed procedure (\% recovery $>98$ ) as follows. Five tablets from each batch were crushed in a mortar. Thereafter, three portions of the 
crushed powder (50 mg each) were weighed and separately placed in $250 \mathrm{ml}$ volumetric flasks, and $0.1 \mathrm{M}$ of $\mathrm{HCl}$ was added to adjust to volume. The mixture was stirred on a magnetic stirrer for $30 \mathrm{~min}$, and the supernatant assayed spectrophotometrically at $289 \mathrm{~nm}$. Drug content was calculated and expressed as \% labeled amount.

\section{Heckel analysis}

Heckel described the increasing densification of tablets with increasing compression pressure $(P)$ via first order kinetics as in Eq 6 [10].

$$
\ln \frac{1}{(1-\mathrm{D})}=\mathrm{kP}+\mathrm{b}
$$

where $D$ is the relative density calculated using Eq 7.

$$
\mathrm{D}=\frac{\mathrm{d}_{\mathrm{app}}}{\mathrm{d}_{\mathrm{tru}}}
$$

$d_{\text {tru }}$ is the true density of filler-binders and $d_{a p p}$ is the apparent density of tablets at the respective compression pressure, which was calculated using Eq 8 [3].

$$
\mathrm{d}_{\text {app }}=\frac{4 \mathrm{~W}_{\mathrm{tab}}}{\pi \mathrm{d}^{2} \mathrm{~h}}
$$

$\mathrm{W}_{\mathrm{tab}}, \mathrm{d}$ and $\mathrm{h}$ are the weight, diameter and thickness of tablets, respectively. Heckel plot for tablets consisting of filler-binders only was constructed by plotting In 1/(1-D) against $P$, and then the value of slope $(k)$ was computed by regression analysis of the linear portion of the plot. The slope value allowed for the interpretation of overall compression behavior of filler-binders.

\section{Statistical analysis}

Independent sample t-test was used to verify significant difference of results of the determined parameters with $p$-value set at < 0.05 . The statistical test was run on an open source software, OpenStat.

\section{RESULTS}

\section{Powder properties}

Scanning electron microscopy (SEM) results demonstrated that MCC and PMD mainly comprised irregular agglomerates of fibrous and polygonal particles, respectively (Figure 1). Particle size $\left(d_{50}\right)$ was $84.91 \pm 1.16$ and $25.96 \pm 0.70 \mu \mathrm{m}$, while polydispersity index (PI) was $2.24 \pm 0.04$ and $3.19 \pm 0.03$ for MCC and PMD respectively, while true density was $1.61 \pm 0.09$ and $1.37 \pm 0.01 \mathrm{~g} / \mathrm{ml}$, respectively. Bulk and tap densities of MCC were $0.38 \pm 0.00$ and $0.48 \pm 0.02 \mathrm{~g} / \mathrm{ml}$, while those of PMD were $0.54 \pm 0.02$ and $0.64 \pm$ $0.01 \mathrm{~g} / \mathrm{ml}$, respectively.

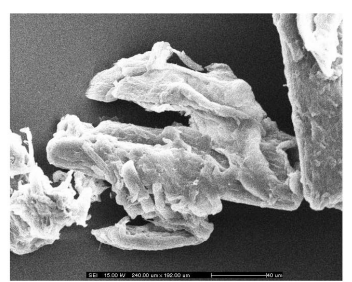

(a)

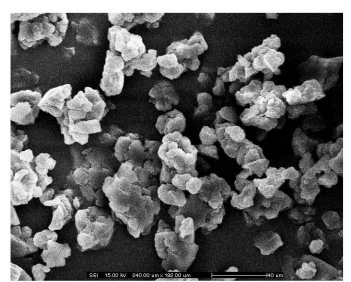

(b)
Figure 1: SEM of (a) MCC and (b) PMD

Compressibility index was $20.88 \pm 2.45$ and $15.17 \pm 4.43 \%$, and Hausner ratio $1.26 \pm$ 0.04 and $1.18 \pm 0.06$, for MCC and PMD, respectively. The volumetric swelling of MCC and PMD was similar, being $21.08 \pm 0.94$ and $19.67 \pm 3.00 \%$, respectively. However, the gravimetric swelling of MCC $(82.28 \pm 2.55 \%)$ was significantly lower than that of PMD $(155.56 \pm 2.91 \%)$.

\section{Tablet properties}

The diameters of tablets made from MCC and PMD were comparable, being in the range of $9.54-9.65 \mathrm{~mm}$. In contrast, the thickness of the tablets was clearly sensitive to the type of filler-binder and compression pressure (Table 1). At all pressures, the tablets made from PMD were thicker than those prepared with MCC. For both filler-binders, the tablet thick- 
Table 1: Properties of tablets made from plain filler-binders

\begin{tabular}{lcccccccc}
\hline $\begin{array}{l}\text { Pressure } \\
\text { (MPa) }\end{array}$ & \multicolumn{2}{c}{$\begin{array}{c}\text { Thickness } \\
(\mathbf{m m})\end{array}$} & \multicolumn{2}{c}{$\begin{array}{c}\text { Crushing strength } \\
\text { (N) }\end{array}$} & \multicolumn{2}{c}{ Friability (\%) } & \multicolumn{2}{c}{$\begin{array}{c}\text { Disintegration } \\
\text { time (min) }\end{array}$} \\
\cline { 2 - 9 } & $\boldsymbol{M C C}$ & $\boldsymbol{P M D}$ & $\boldsymbol{M C C}$ & $\boldsymbol{P M D}$ & $\boldsymbol{M C C}$ & $\boldsymbol{P M D}$ & $\boldsymbol{M C C}$ & $\boldsymbol{P M D}$ \\
\hline 34 & $3.33 \pm 0.03$ & $4.46 \pm 0.06^{*}$ & $203.8 \pm 11.9$ & $49.2 \pm 13.6^{*}$ & 0.14 & 2.99 & $>60$ & $0.43 \pm 0.09$ \\
69 & $3.09 \pm 0.02$ & $4.26 \pm 0.09^{*}$ & $301.7 \pm 11.2$ & $102.7 \pm 12.6^{*}$ & 0.18 & 0.80 & $>60$ & $0.43 \pm 0.07$ \\
103 & $3.00 \pm 0.02$ & $3.80 \pm 0.13^{*}$ & $358.0 \pm 7.8$ & $196.6 \pm 76.3^{*}$ & 0.04 & 0.04 & $>60$ & $1.36 \pm 1.12$ \\
137 & $2.96 \pm 0.02$ & $3.77 \pm 0.06^{*}$ & $404.7 \pm 7.2$ & $233.7 \pm 46.1^{*}$ & 0.06 & 0.04 & $>60$ & $1.02 \pm 0.40$ \\
172 & $2.95 \pm 0.02$ & $3.61 \pm 0.07^{*}$ & $414.6 \pm 5.9$ & $268.4 \pm 25.4^{*}$ & 0.07 & 0.05 & $>60$ & $2.77 \pm 1.99$ \\
206 & $2.93 \pm 0.05$ & $3.57 \pm 0.04^{*}$ & $399.5 \pm 5.3$ & $416.6 \pm 38.6$ & 0.02 & 0.04 & $>60$ & $5.54 \pm 2.46$ \\
240 & $2.97 \pm 0.03$ & $3.65 \pm 0.06^{*}$ & $411.8 \pm 3.8$ & $413.4 \pm 29.6$ & 0.11 & 0.04 & $>60$ & $6.24 \pm 2.14$ \\
275 & $2.94 \pm 0.02$ & $3.62 \pm 0.05^{*}$ & $414.6 \pm 7.6$ & $458.9 \pm 36.1^{*}$ & 0.07 & 0.08 & $>60$ & $7.69 \pm 1.16$ \\
309 & $2.96 \pm 0.02$ & $3.54 \pm 0.08^{*}$ & $417.0 \pm 4.9$ & $>500$ & 0.11 & 0.05 & $>60$ & $9.56 \pm 1.14$ \\
344 & $2.95 \pm 0.03$ & $3.60 \pm 0.03^{*}$ & $408.9 \pm 10.3$ & $>500$ & 0.02 & 0.02 & $>60$ & $7.95 \pm 1.17$ \\
\hline
\end{tabular}

* Indication of significant difference $(p<0.05)$ compared with MCC

ness decreased at low compression pressures but thereafter remained constant when compression pressure was further increased. Compared with PMD, the MCC tablets had higher crushing strengths under applied compression pressure ranging from 34 to $206 \mathrm{MPa}$ (Table 1). In this range of pressure, the crushing strength of MCC tablets increased with increasing compression pressure. However, increase in compression pressure from 206 to $344 \mathrm{MPa}$ did not cause further increase in crushing strength. PMD gave softer tablets at low compression pressures $(<206 \mathrm{MPa})$. Nonetheless, the crushing strength of PMD tablets dramatically increased as compression pressure was increased to $344 \mathrm{MPa}$. Interestingly, as the compression pressure was increased from 206 to $344 \mathrm{MPa}, \mathrm{PMD}$ produced stronger tablets than MCC. PMD tablets compressed at $\geq 309 \mathrm{MPa}$ were so strong ( $>500 \mathrm{~N}$ ) that they could not be evaluated with the hardness tester.

Table 1 also presents the friability and disintegration time of the tablets. Almost all the tablets showed low friability $(<1 \%)$. MCC tablets did not completely disintegrate within 60 min. As with PMD tablets, disintegration time increased as crushing strength increased. Nonetheless, all PMD tablets completely disintegrated within $10 \mathrm{~min}$.
MCC and PMD containing 10 and $100 \mathrm{mg}$ propranolol hydrochloride, are tagged with 10 and 100, respectively. The drug content of $\mathrm{MCC} / 10, \mathrm{MCC} / 100, \mathrm{PMD} / 10$ and $\mathrm{PMD} / 100$ tablets was $97.00 \pm 0.96,97.24 \pm 4.35,96.82$ \pm 1.44 and $105.16 \pm 4.89 \%$, respectively, which are within the USP required limits (90 $110 \%)$. Tablets prepared with PMD were thicker than those produced with MCC, being $3.56 \pm 0.02,3.56 \pm 0.01,3.02 \pm 0.01$ and 3.15 $\pm 0.02 \mathrm{~mm}$ for $\mathrm{PMD} / 10, \mathrm{PMD} / 100, \mathrm{MCC} / 10$ and $\mathrm{MCC} / 100$, respectively. These data followed the pattern for those for plain fillerbinder tablets. The crushing strength of $\mathrm{MCC} / 10$ and $\mathrm{PMD} / 10$ was $256.7 \pm 8.8$ and $406.1 \pm 17.3 \mathrm{~N}$, respectively, which were lower than those of the plain filler-binder tablets. When the dose of drug was increased from 10 to $100 \mathrm{mg}$, the crushing strength of tablets decreased to $208.1 \pm 5.3$ and $177.9 \pm$ $28.5 \mathrm{~N}$ for $\mathrm{MCC} / 100$ and $\mathrm{PMD} / 100$, respectively. However, these tablets exhibited low friability, which was $0.11,0.30,0.01$ and $0.59 \%$ for $\mathrm{MCC} / 10, / 100, \mathrm{PMD} / 10$ and $/ 100$, respectively.

PMD/10 and PMD/100 tablets disintegrated completely in $4.59 \pm 0.82$ and $5.37 \pm 1.51$ min, similar to those made from the plain resin. The disintegration time of $\mathrm{MCC} / 10$ and $\mathrm{MCC} / 100$ was $10.76 \pm 0.85$ and $9.89 \pm 1.03$ min, respectively, which were shorter than those of tablets made from plain MCC (> 60 
$\min$ ). The dose of drug (10 or $100 \mathrm{mg}$ ) had no significant effect on the disintegration time of tablets made from either of the filler-binders ( $p$ $>0.05$ ).

The dissolution profiles of the tablets are illustrated in Figure 2. Drug dissolved faster from PMD tablets than from MCC tablets. After $60 \mathrm{~min}$, drug dissolution from the tablets was virtually complete, being $99.93 \pm 4.22$, $97.84 \pm 1.71,99.80 \pm 1.61$ and $94.98 \pm 1.48$ $\%$ for $\mathrm{PMD} / 10, \mathrm{PMD} / 100, \mathrm{MCC} / 10$ and MCC/100, respectively. ]

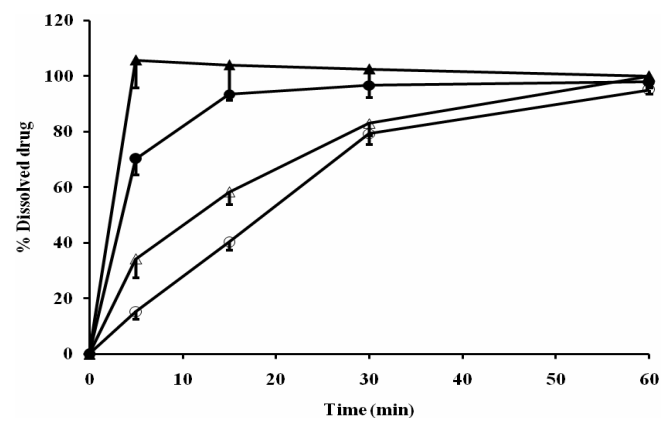

Figure 2: Dissolution profiles of $\operatorname{MCC} / 10(\Delta)$,

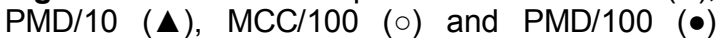
tablets

The linear portion of the Heckel plots is shown in Figure 3. The compression behavior of both filler-binders substantially fitted Heckel equation $\left(R^{2}>0.90\right)$. The value of the Heckel slope for PMD $\left(5.02 \times 10^{-3} \mathrm{MPa}^{-1}\right)$ was very close to that for MCC $\left(5.12 \times 10^{-3} \mathrm{MPa}^{-1}\right)$.

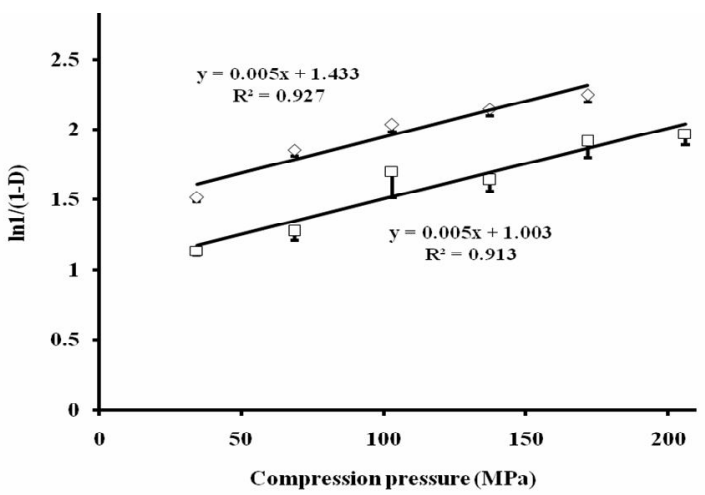

Figure 3: Linear Heckel plots for plain MCC $(\diamond)$ and PMD ( $\square$ ) tablets

\section{DISCUSSION}

The observed morphology of MCC agreed with an earlier finding on the filler [1]. The particle size of PMD was smaller $(p<0.05)$ than that of MCC but its size distribution was broader than that of MCC $(p<0.05)$. The true density of PMD was lower than that of MCC $(p<0.05)$. Generally, a solid substance with a low degree of crystallinity also displays low true density [11,12]. PMD is amorphous [13] while MCC is crystalline [12], thus exhibiting the lower true density. PMD provided the higher bulk and tap densities as compared with MCC $(p<0.05)$. This might primarily result from the smaller size of PMD which was able to fill into smaller interspaces of the powder bed [10].

Compressibility index and Hausner ratio data indicate that the flowability of PMD was not significantly higher than that of MCC $(p>$ 0.05), which exhibited good and fair-topassable flowability, respectively [8]. The slightly superior flowability of PMD may be due to its less fibrous shape and higher bulk and tap densities.

The degree of gravimetric swelling of PMD was twice that of MCC $(p<0.05)$, indicating that the resin could adsorb a great amount of water, this is probably as a result of the fact that the carboxyl group $(-\mathrm{COOH})$ of the resin was more dissociable, and thus had a higher affinity for water than the hydroxyl group ($\mathrm{OH})$ of MCC. However, MCC and PMD exhibited the similar degree of volumetric swelling $(p>0.05)$, implying that there was no correlation between gravimetric and volumetric swelling.

At all compression pressures, the tablets made from PMD were thicker than MCC $(p<$ $0.05)$. The cause may be attributed to the different true density of the filler-binders. Theoretically, the greater the true density the less the volume occupied by a unit weight of a material, and hence the smaller the tablet obtained from the filler. Since PMD possesses 
a lower true density than MCC, PMD tablets would be expected to show greater.

MCC is well known to exhibit excellent compressibility even at low pressures [1]. This is supported by the findings of the present work. However, PMD showed better compressibility than MCC at high compression pressure due probably to stronger interparticular bonding of the former as it could form double hydrogen bonds between the carboxyl groups, as the structures in Fig 4 illustrates [11]. This effect was not exerted at relatively low compression pressure because of the higher elastic phase in PMD and hence its greater resistance to compression [14].

The low friability of all plain MCC tablets can be attributed to the excellent compressibility of MCC, which yielded tablets with high crushing strengths, even at low compression pressure. In addition, the fibrous morphology of MCC might have facilitated locking between particles, leading to low friability [3]. The low friability of plain PMD tablets may be due to their high crushing strengths.

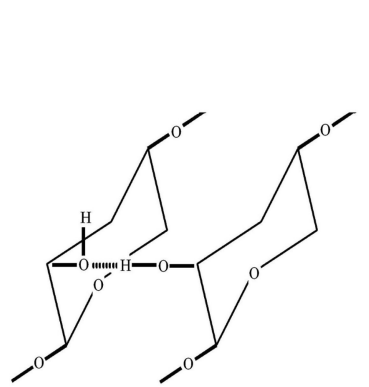

(a)

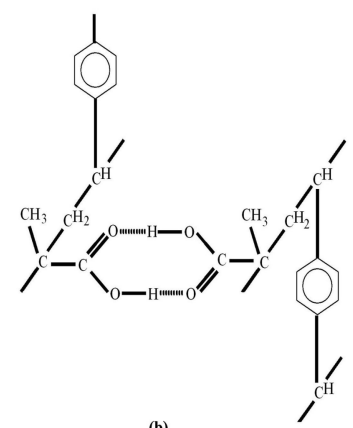

be linked to the gravimetric swelling of PMD which was about twice that of MCC although they exhibited similar degree of volumetric swelling.

Tablets containing the drug exhibited lower crushing strength than the tablets made with only filler-binders. This is to be expected since the drug is poorly compressible and would have hindered the formation of bonds between the filler-binder particles. The lower disintegration time of the drug-loaded tablets when compared with the plain filler-binder tablets, prepared may be due to the high solubility of the drug which after dissolving in the tablet matrix, created aqueous channels in the tablet that aided disintegration.

Drug dissolution from PMD tablets was faster than from MCC, which can be attributed to the shorter disintegration time of the former. It is, however, not clear why tablets with the higher drug content exhibited slower dissolution than those with lower drug content. However, based on Noyes-Whiney equation, the dissolution rate is proportional to the gradient between the drug solubility $\left(C_{s}\right)$ and concentration $\left(C_{b}\right)$ in the bulk solution, i.e., $\left(C_{s}-C_{b}\right)$ [11]. It should therefore be expected that the higher-dose tablets will produce a higher concentration of the dissolved drug in the dissolution medium. Since the solubility parameter is constant, this would in turn lower dissolution gradient, leading possibly to lower rate of drug dissolution than for lower-dose tablets. Interestingly, both MCC and PMD tablets achieved virtually complete dissolution of the drug, indicating that the drug was not bound to the resin (PMD).

Figure 4: Possible hydrogen bonds formed by (a) MCC and (b) PMD

Although MCC tablets swelled in water, they did not completely disintegrate within $60 \mathrm{~min}$. A similar observation had earlier been made $[3,4]$. In contrast, PMD tablets completely disintegrated within $10 \mathrm{~min}$, including those with higher crushing strength than MCC tablets. It would appear that PMD possesses an inherent disintegrant property which may
The slope of the Heckel plot may be indicative of the plasticity of filler-binders that deform under compression. Typically, a higher value of the slope is related to a greater degree of plastic deformation $[3,10]$. MCC is known to deform plastically under compression $[1,3]$. The Heckel slopes for MCC and PMD were comparable, thus indicating that PMD probably also undergoes plastic deformation under compression. When viewed by SEM 
(not shown here), no substantial fragmentation of compressed MCC and PMD particles was observed.

\section{CONCLUSION}

PMD had good compressibility at high compression pressures. The resin seems to undergo plastic deformation under compression just like MCC. PMD tablets, with and without propranolol hydrochloride, showed adequate crushing strength and friability, as rapid disintegration and dissolution of the drug in the absence of a disintegrant. Consequently, PMD appears to be suitable as a filler-binder for immediaterelease direct compression tablets.

\section{ACKNOWLEDGEMENT}

The authors wish to thank the Silpakorn University Research and Development Institute for funding this research.

\section{REFERENCES}

1 Bolhuis, Gerad K.; Chowhan, Zak T. Materials for direct compression. In: Alderborn, Goran; Nystrom, Christer, editors. Pharmaceutical powder compression technology. New York: Marcel Dekker; 1996; pp 419-500.

2 Bolhuis GK, Eissens AC, Zoestbergen E. DC calcium lactate, a new filler-binder for direct compression of tablets. Int J Pharm 2001; 221: 77-86.

3 Kumar V, Reus-Medina ML, Yang D. Preparation, evaluation, and tabletting properties of a new cellulose-based pharmaceutical aid. Int $J$ Pharm 2002; 235: 129-140.

4 Medina MLR, Kumar V. Evaluation of cellulose II powders as a potential multifunctional excipient in tablet formulations. Int $\mathrm{J}$ Pharm 2006; 332 . 31-35.

5 Borodkin, Saul. Ion exchange resins and sustained release. In: Swarbrick, James; Boylan, James C., editors. Encyclopedia of pharmaceutical technology. New York: Marcel Dekker; 1993; pp 203-216.

6 Akkaramongkolporn P, Wongsermsin K, Opanasopit $P$, Ngawhirunpat $T$. Comparison between the effect of strongly and weakly cationic exchange resins on matrix physical properties and the controlled release of diphenhydramine hydrochloride from matrices. AAPS PharmSciTech 2010; 11: 1104-1114.

7 Pongjanyakul $T$, Priprem $A$, Chitropas $P$, Puttipipatkhachorn S. Effect of polysulfonate resins and direct compression fillers on multiple-unit sustained-release dextromethorphan resinate tablets. AAPS PharmSciTech 2005; 6: article 28.

8 The United State Pharmacopoeia 29. Rockville MD: United State Pharmacopoeial Convention: 2006.

9 Bajpai SK, Sharma S. Investigation of swelling/degradation behaviour of alginate beads crosslinked with $\mathrm{Ca}^{2+}$ and $\mathrm{Ba}^{2+}$ ions. React Funct Polym 2004; 59: 129-140.

10 Zhang Y, Law Y, Chakrabarti S. Physical properties and compact analysis of commonly used direct compression binders. AAPS PharmSciTech 2003; 4: article 62.

11 Martin A, Swarbrick J, Cammarata A. Physical Pharmacy.edn 3, Philadelphia: Lea \& Febiger; 1983; pp 409, 623.

12 Kumar V, Kothari SH. Effect of compressional force on the crystallinity of directly compressible cellulose excipients. Int J Pharm 1999; 177: 173-182.

13 Pisal S, Zainnuddin R, Nalawade $P$, Mahadik $K$, Kadam S. Molecular properties of ciprofloxacinindion234 complexes. AAPS PharmSciTech 2004; 5: article 62.

14 Tatavarti AS, Muller FX, Hoag SW. Evaluation of the deformation behavior of binary systems of methacrylic acid copolymers and hydroxypropylmethylcellulose using a compression simulator. Int J Pharm 2008; 348 . 46-53. 